\title{
Prehospital care in Malaysia: issues and challenges
}

Keng Sheng Chew is a Senior Lecturer/Emergency Physician, Emergency Medicine Department, School of Medical Sciences, Universiti Sains Malaysia. Hiang Chuan Chan is the State Emergency Physician of Sarawak/Head of Department, Emergency Medicine Department, Sarawak General Hospital. Email for correspondence: cksheng74@yahoo.com

\section{Abstract}

Prehospital care is defined as the phase of patient care from the point of injury or illness to the place of definitive treatment. As such, it is imperative that the right patient is transported to the right place of care within the right time frame via the right mode of transportation by the right personnel. In this article, the authors explore seven components that are essential in the initial stage of any prehospital care system development, viz., the components of manpower, training, communication, transportation, facilities, access to care and coordinated patient record keeping. The authors then address issues and challenges in these seven components within the Malaysian context. Because of geopolitlcal and logistic differences from one locality with another, it is not possible for a "one-size-fit-all" solution to these issues and challenges within Malaysia. Ultimately, any effort to develop the prehospital care system should not be a mere stop gap measure, rather, it should address fundamental root problems in order to ensure sustainability and continuity of effort.

\section{Key words}

- Emergency medical services $\bullet$ Prehospital care $\bullet$ Malaysia

Accepted for publication 14 July 2011

$\mathrm{D}$ efined as the phase of care necessary to get a patient from the point of injury or illness to the place of definitive treatment, prehospital care is becoming increasingly important in many parts of the world including Malaysia (Sikka and Margolis 2005). As the economy progresses, health network improves and people tend to live longer. Rapid urbanization occurs with increasing numbers of people shifting out to larger cities.

\section{Introduction to Malaysia}

Malaysia covers an area of approximately 330803 $\mathrm{km}^{2}$, consisting of Peninsular Malaysia and the states of Sabah and Sarawak and Federal Territory Labuan in the northwestern coastal area of Borneo Island (Department of Statistics Malaysia, 2011c). Large cities such as Kuala Lumpur has a population density of $7089 / \mathrm{km}^{2}$; whereas interior places of the state of Sarawak such as Belaga and Kapit have a population density of merely 2 and 4/ $\mathrm{km}^{2}$ (Department of Statistics Malaysia, 2011a). As people are moving into cities, there is more trauma related emergencies, especially motor vehicle accidents and thus, a greater need for prehospital care services. Currently, only $10-30 \%$ of emergency cases are managed by existing prehospital EMS agencies. Thus, there is still a large proportion of patients that are brought in by passerbys or via their own transportation to the hospitals.

Life expectancy for Malaysian male and female has been steadily improving from 71.5 years (2006) to 71.7 years (2010) for male and 76.3 years (2006) to 76.6 years (2010) for female (Department of Statistics Malaysia, 2011b). The percentage of people aged 65-years-old and above has increased from $4.0 \%$ (2000) to $4.7 \%$ (2010) (Department of Statistics Malaysia, 2011b).

As people live longer, disease pattern changes, and this results in an increase in the number of cardiovascular disease cases. For example, in 2009, cardiovascular diseases was the number one (16.1\%) cause of death in the Malaysian Ministry of Health hospitals and accident-related injuries came the seventh $(4.9 \%)$ cause of death (Ministry of Health Malaysia, 2011). The chance of survival in these cardiovascular diseases is often influenced by timedependent interventions. For example, a patient with acute ST-elevation myocardial infarction requires thrombolytic therapy as early as possible.

It is stipulated that the time frame from a patient's arrival at the emergency department to the initiation of thrombolytic therapy (known as the 'door-toneedle' time) should be within 30 minutes (Antman et al, 2004) although in reality, the mean 'door-toneedle' time shown in a recent single centre, local study in Malaysia was about 105 minutes (Lee et al, 2008).

Similarly, for a cardiac arrest victim, chance of survival is dependent upon the prompt initiation of chest compression (Sasson et al, 2010).

However, the ambulance response time in Malaysia varies from approximately $15.2 \mathrm{~min}$ to 


\section{Table 1. Five types of prehospital care system models}

\begin{tabular}{|c|c|}
\hline System model & Description \\
\hline Hospital-based system & $\begin{array}{l}\text { In this system, the emergency medical services (EMS) personnel are trained and managed at the hospital level. This system } \\
\text { is usually the easiest to initiate and maintain as medical control issues are less complicated and can be incorporated into } \\
\text { the existing hospital system seamlessly. This type of system is commonly seen in newly developed systems }\end{array}$ \\
\hline $\begin{array}{l}\text { Jurisdiction-directed } \\
\text { system }\end{array}$ & $\begin{array}{l}\text { This system originates from the municipal or district level, and maybe linked to the fire response with contracted } \\
\text { physicians providing medical oversight }\end{array}$ \\
\hline Private system & This system, as the name goes, is maintained by private organisations \\
\hline Volunteer system & This system is formed by a network of volunteers who are privately trained \\
\hline \multirow[t]{2}{*}{ Complex system } & $\begin{array}{l}\text { This system is a combination of any of the above system types and evolve secondary to resource } \\
\text { limitation as well as the need for shared resources. }\end{array}$ \\
\hline & From: Van Rooyen et al (1999) \\
\hline
\end{tabular}

25.6 min depending on the location and traffic congestion (Hisamuddin et al, 2007) which may indicate that public members play a crucial role in starting bystander CPR prior to the arrival of ambulances. In a small recent study, we found that bystander CPR was only performed in $9 \%$ of outof-hospital non-traumatic adult cardiac arrest cases (Chew et al, 2008b).

\section{Prehospital care: a complex system}

According to Van Rooyen et al (1999), prehospital systems can be divided into five different types of system models. These five models are

- Hospital-based systems

- Jurisdiction-directed systems

- Private systems

- Volunteer systems

- Complex systems.

The details of each of these systems are described in Table 1. Based on the above classification, prehospital care in Malaysia can be considered as a complex system with the hospital-based system as the oldest and main service provider. Most of these hospital-based EMS services are provided by the public or government hospitals. The Civil Defence Department is the second largest agency, providing 24-hour of prehospital coverage in most urban areas of every state in Malaysia. Private systems do play a minor role, but these are usually paid services provided by private medical centres. Jurisdictiondirected system is rudimentary in Malaysia, provided mostly by the police and fire department personnel. These personnel are not legally bound to provide medical care. Their main emphasis is on rapid transportation of emergency patients with bare minimum first aid provision. A volunteer-based system, on the other hand, is a well-established system with the St John Ambulance Malaysia and the Malaysian Red Crescent being the main key players. This volunteer-based system, with their own training programmes and hardware (including vehicles) often serves as a reliable extension arm to complement services by the hospital-based system.

Ultimately however, the aim of any prehospital care is to decrease the morbidity and mortality associated with sudden medical and traumatic emergencies (Sikka and Margolis, 2005). technologyintensive model of prehospital care may be not always the most appropriate and with its relatively high cost budget, this is beyond the capability of most developing countries.

Furthermore, high technology does not always translate into high-quality care (Garfield and Rodriguez 1985). On the contrary, prehospital care must exist within a country's cultural and geopolitical framework and the boundary of its supporting health care infrastructure (Sikka and Margolis 2005).

Therefore, it is imperative to have in-depth study and to understand the current level of infrastructure development and healthcare facilities in a country before embarking on the development of EMS. In fact, not only a great disparity exists in terms of the level of EMS development from country to country; even within a nation itself, the level of EMS development differs from one locality with another.

\section{Malaysia and EMS}

In Malaysia, a whole gamut of different EMS services exists, ranging from providing basic transportation ('scoop and run') only, to providing first aid or basic life support care up to offering advanced care with the presence of trained healthcare providers. In the interior parts of Sabah and Sarawak states, accessibility of health care is extremely limited, and 


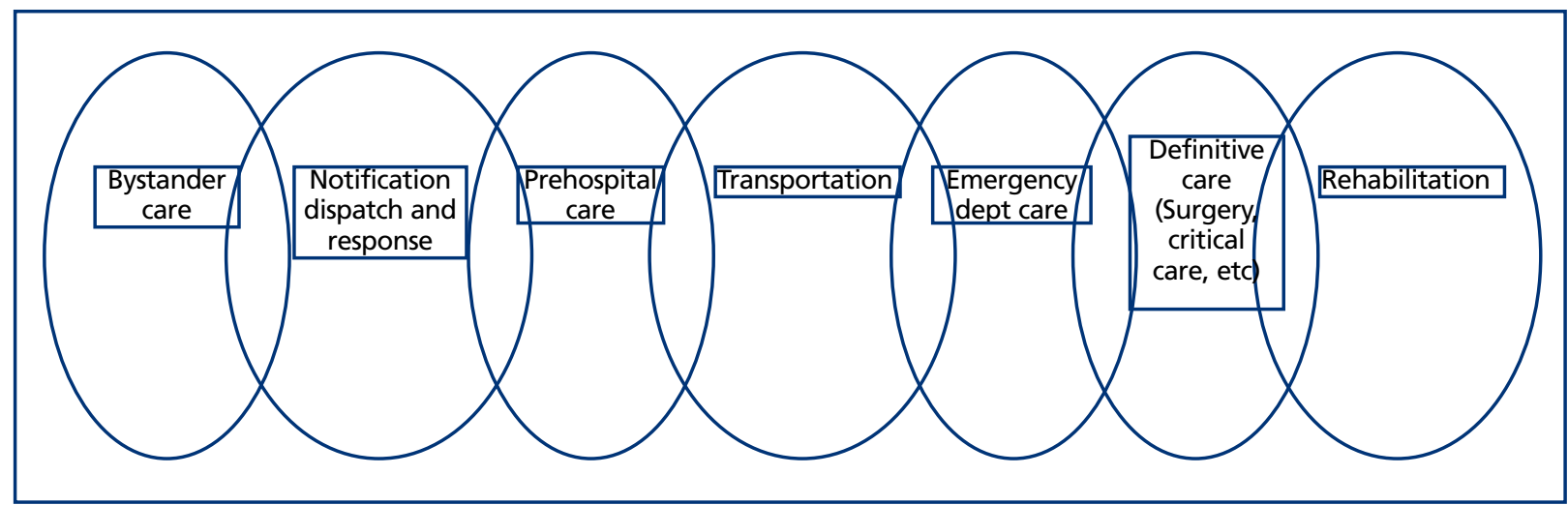

Figure 1. This illustrates the importance of a seamless continuum of care that begins right from the role of the public or bystander in providing necessary first responder care, recognition and notification of emergency situations up to disposition of patients to appropriate, definitive care plans. Prehospital care is just one component of this chain of resources (Sikka and Margolis, 2005)

\section{Table 2. Essential EMS components}

To be implemented in the initial stage
Manpower
Training
Communication
Transportation
Facilities
Access to care
Coordinated patient record-keeping

To be implemented gradually as the system matures

Critical care units

Public safety agencies

Consumer participation

Patient transfer

Public information and education

Review and evaluation

Disaster plan

Mutual aid

sometimes impossible especially at night and during bad weather. In areas such as these, developing critical infrastructure for initial resuscitation and stabilization, as well as efficient and effective retrieval medicine, may be the way forward.

\section{Flying doctor services}

In Sarawak, one of the ways to overcome this logistic difficulty is the use of the 'Flying Doctor Services' (FDS), introduced in 1973. The aim of this service is to provide basic health services to people living in remote areas. At that time, this service was operated by using three private helicopters that were rented on a contractual basis. This service covers up to 141 remote locations in rural parts of Sarawak with about 70000 outpatients, children and antenatal cases every year.
This FDS team comprises of a medical officer, a medical assistant and two community nurses who visit the locations once every one or two months. Besides, the FDS also provides medical emergency evacuation (MEDEVAC) of seriously ill or injured patients from these remote localities to the nearest appropriate hospitals (Sarawak Government Portal, 2011). At the current moment, the air medical services in Sarawak has been expanded to five helicopters; with the MEDEVAC services having two specific twin-engine helicopter on standby at all time and another three helicopters for uninterrupted FDS services.

\section{Integrated resources}

Furthermore, as mentioned by Sikka and Margolis (2005), prehospital care is only one part of a chain of integrated resources (Figure 1). For a healthcare system to improve, other components of this chain of resources must be developed in tandem as well. Therefore, public education (including education on basic life support), access to care, staff training, equipment, etc. must be maximized. By merely developing prehospital care without developing these other components may paradoxically result in fragmentation and wastage of resources.

Van Rooyen et al (1999) outlined 15 essential EMS components as stipulated under the Emergency Medical Systems Act (Table 2). Out of these 15 components, Van Rooyen et al (1999) singled out seven components that should be implemented at the initial stage with gradual implementation of the other eight components as the system matures. The remainder of this article will discuss on specific issues and challenges we face in these seven initial essential components.

\section{Manpower}

Prehospital care in Malaysia is currently usually manned by the paramedics and a driver; and 


\section{Table 3. Common types of land ambulances in Malaysia}

$\begin{aligned} & \text { Types of land ambulances } \\ & \text { Grade } A 1\end{aligned}$
$\begin{aligned} & \text { All of Grade A equipment plus specialised machines such as neonatal incubator, mobile intensive care } \\ & \text { facilities, etc }\end{aligned}$
All of Grade B equipment plus transport ventilator, defibrillator and cardiac monitor
Grade B
Others

occasionally but not necessarily, together with a medical doctor. Therefore, the staff that are involved in EMS have differing levels of knowledge, skills and competency. This can result in inconsistency of care, non adherence to standard management protocol and inter-facility transfer policy.

\section{Training}

There is no standardized certification for prehospital care providers within Malaysia. The paramedics staffing the ambulances have formal training in general paramedical sciences, but are not necessarily trained in prehospital care (Hisamuddin et al 2007). Most of the time, the driver has no formal medical training and neither is he a specifically trained to handle ambulances or EMS vehicles. As yet, there is no specific national prehospital care training institute. Although few private institutions have started their own paramedical prehospital care training programmes, their curriculum is not a standardized curriculum.

\section{Communication}

In July 2007, the Malaysian government has introduced the 'One nation, one number' system of the universal emergency number '999' for all types of emergencies, regardless of whether it is healthrelated or non-health related (Chew et al, 2008a). This has made it easier for the public to activate the EMS as people do not need to remember too many numbers as they previously did-'991' for Civil Defence Department, '994' for Fire and Rescue and '999' for police. Nonetheless, prank calls are still a problem in more than $90 \%$ of the emergency number usage (Chew et al, 2008a) despite the active public awareness campaign that making prank calls is an offence punishable to a maximum fine of RM50000 (£10 000) or imprisonment for a term not exceeding one year or both under section 233 of the Malaysian Communications and Multimedia Act 1998 (Malaysian Communications and Multimedia Commission, 2011).

\section{Another problem} that we face is the lack of uniformed EMS communication between different agencies. Each individual agency is relying on their own communication system of call-receiving and dispatching of EMS teams (Hisamuddin et al, 2007). This can potentially result in incoordination,

inappropriate transfer, overlapping and wastage of resources (for example, when more than one ambulance arrives at the site of accident to transport one victim). Realizing this difficulty, the Malaysian government introduced the Government Integrated Radio Network (GIRN) last year. Basically, GIRN is an attempt to close this interagencies communication gap between the fire department, the police, the EMS and other public safety agencies. However, the main limiting factor of GIRN is its restricted coverage to certain densely populated areas only.

\section{Transportation and facilities}

There are few types of land ambulances in Malaysia (Table 3). The high-end types (Grade A or A1) are available in larger cities and Grade B are available in district hospitals or rural health centres. 


\section{Key points}

- The ultimate aim of any prehospital care, irrespective of the model system employed, is to reduce morbidity and mortality.

- Sophisticated technology may not always be the pragmatic or cost effective solution particularly in situations where the surrounding or supporting infrastructures are yet to have developed in tandem.

- The development of any prehospital care system must be structured within the confine of a country's geopolitical and cultural boundaries.

- Any effort to develop the prehospital care system should be sustainable, and not merely a stop gap measure.

\section{Access to care}

Since the 1970s, the Ministry of Health in Malaysia has taken steps to establish an extensive network of health care services in the country. Currently a total of $97 \%$ of the rural population have access to healthcare services within a $3 \mathrm{~km}$ radius from their residence and in East Malaysia, more than $50 \%$ of rural folks have access to health care services within a $5 \mathrm{~km}$ radius (Krishnaswamy et al, 2009). In areas such as the interior parts of Sarawak, health care services are limited. In such cases, the concept of self-care and community active participation is vital. The Sarawak state government, for example has started training community health volunteers under the Village Health Promoter (VHP) programme to supplement the existing healthcare services provided by the government (Sarawak Government Portal, 2011).

\section{Coordinated patient record-keeping}

There is no single coordinated patient recordkeeping system in Malaysia. Not only that the patient's record notes in private medical centres differ from that in government healthcare centres, but even within government healthcare services itself, patient record system differs from centre to centre. In remote areas where it is difficult to retrieve the previous and concurrent treatment given in another centre, this can pose considerable diagnostic and therapeutic problems.

Again, a unique feature in the Sarawak state is the use of 'home-based' medical records. This system was introduced in the 1970s initially for the child health records (including immunisation records), and then it was extended in the 1980s for antenatal records and since 1992, it has been extended for the entire outpatient medical cases. The main advantage of this system is that it ensures a seamless continuum of care for the patient as the patient themselves hold a copy of all treatment given in any government centres in the state of Sarawak (Sarawak Government
Portal 2011). Unfortunately, over the recent years, a few medico-legal issues have cropped up, posing huge challenges to this 'home based' medical records system. This has prompted the government to look into using digital system as the way forward.

\section{Conclusion}

In summary, although prehospital care services in Malaysia have improved considerably, there is still much room for further improvement. The bottom line, however, is that because of the varied sociocultural and geographical differences in different parts of Malaysia, there is no 'one-size-fit-all' system for the entire prehospital care development. In fact, any measure considered for the development of prehospital care in Malaysia should ensure its continuity and sustainability and not just a mere 'stop-gap' measure.

Antman EM, Anbe DT, Armstrong PW et al (2004) ACC/AHA guidelines for the management of patients with ST-elevation myocardial infarction-executive summary. A report of the American College of Cardiology/American Heart Association Task Force on Practice Guidelines (Writing Committee to revise the 1999 guidelines for the management of patients with acute myocardial infarction). J Am Coll Cardiol 44(3): 671-719

Berg RA, Hemphill R, Abella BS et al (2010) Part 5: Adult Basic Life Support: 2010 American Heart Association Guidelines for Cardiopulmonary Resuscitation and Emergency Cardiovascular Care. Circulation 122(18 Suppl 3): S685-705

Chew KS, Idzwan ZM, Hisamuddin NA et al (2008) Cardiopulmonary resuscitation: the short comings in Malaysia. Malaysian J Med Sciences 14(2): 23-5

Chew KS, Mohd Idzwan Z, Nik Hishamuddun NA et al (2008) How frequent is bystander cardiopulmonary resuscitation performed in the community of Kota Bharu, Malaysia? Singapore Med J 49(8): 636-9

Department of Statistics Malaysia (2011) Basic population characteristics by administrative districts 2010. http://tinyurl. com/3w82ga6 (accessed 10 August 2011)

Department of Statistics Malaysia (2011). Demographic indicators Malaysia 2010. http://tinyurl.com/3e394rh (accessed 10 August 2011)

Department of Statistics Malaysia (2011) Yearbook of Statistics 2009. http://tinyurl.com/3oc2s9v (accessed 10 August 2011)

Garfield RM, Rodriguez PF (1985) Health and health services in Central America. Jama 254(7): 936-43

Hisamuddin NA, Hamzah MS, Holliman CJ (2007) Prehospital emergency medical services in Malaysia.J Emerg Med 32(4): 415-21

Krishnaswamy S, Subramaniam K, Low WY et al (2009) Factors contributing to utilization of health care services in Malaysia: a population-based study. Asia Pac J Public Health 21(4): 442-50

Lee YY, Tee MH, Zurkurnai Y et al (2008) Thrombolytic failure with streptokinase in acute myocardial infarction using electrocardiogram criteria. Singapore Med J 49(4): 304-10

Malaysian Communications and Multimedia Commission portal (2011) Number of fake calls to 999 still alarming. http://tinyurl. com/3cpaelo (accessed 10 August2011).

Ministry of Health Malaysia Official web portal (2011). Statistic Health Facts 2009. http://tinyurl.com/43v8su5 (accessed 10 August 2011)

Sasson C, Rogers MA, Dahl J et al (2010) Predictors of survival from out-of-hospital cardiac arrest: a systematic review and metaanalysis. Circ Cardiovasc Qual Outcomes 3(1): 63-81

Sarawak Government Portal (2011) Health-Medical Care Services. http://tinyurl.com/3vx8eh4 (accessed 10 August 2011)

Sikka N, Margolis G (2005) Understanding diversity among prehospital care delivery systems around the world. Emerg Med Clin North Am 23(1): 99-114

Van Rooyen MJ, Thomas TL, Clem KJ (1999). International emergency medical services: assessment of developing prehospital systems abroad. J Emerg Med 17(4): 691-6 